\title{
Enhancing the Performance of Polysulfone Ultrafiltration Membranes by Mixing with Polyacrylic Acid for Canal Water Treatment
}

\author{
Mohamed Said Abdel Aal ${ }^{a, b^{*}}$, Abdel Monem Mohamed Ahmed ${ }^{\text {a }}$, Hanaa Hammam \\ Abdel Rahman ${ }^{a}$, Sherif Hussein Kandil ${ }^{c}$ \\ ${ }^{a}$ Faculty of Science, Alexandria University, Egypt \\ ${ }^{\mathrm{b}}$ Abu Qir Fertilizers Company AFC, Alexandria, Egypt \\ ${ }^{c}$ Institute of Graduate Studies and Research IGSR, Alexandria University, Egypt \\ * Corresponding author's E-mail address: chemist.msaid@yahoo.com, Tel.: +201006161871 \\ Received: 15 October 2018, Revised: 1 November 2018, Accepted: 16 November 2018
}

\begin{abstract}
A B S T R A C T
We developed some Ultrafiltration (UF) membranes based on polysulfone (PSF) and poly acrylic acid (PAA) mixture. The ultrafiltration membranes were prepared by the phase inversion technique using Dimethylformamide (DMF) as a solvent. Immobilization of PAA in PSF matrix was confirmed by Fourier transform infrared spectroscopy (FTIR). The membranes have an asymmetric structure, as revealed by scanning electron microscopy (SEM). Natural water from Mahmoudia canal (a subdivision of the Nile River) is used as feed water. The permeate flux reached $120.0 \mathrm{l} / \mathrm{m}^{2} . h r$. The hydrophilicity measured by contact angle was enhanced by the addition of PAA to reach $66.0^{\circ}$. The prepared membranes showed good tensile strength that reached 7.2 $\mathrm{MPa}$. Turbidity rejection and dissolved organic carbon (DOC) rejection reached $98.4 \%$ and $65 \%$, respectively. These performances obtained at ambient operating conditions, make the fabricated membranes attractive for canal water treatment.
\end{abstract}

Keywords: Ultrafiltration; Membranes; Polysulfone; Polyacrylic acid.

G R A P H I C A L A B S T RACT

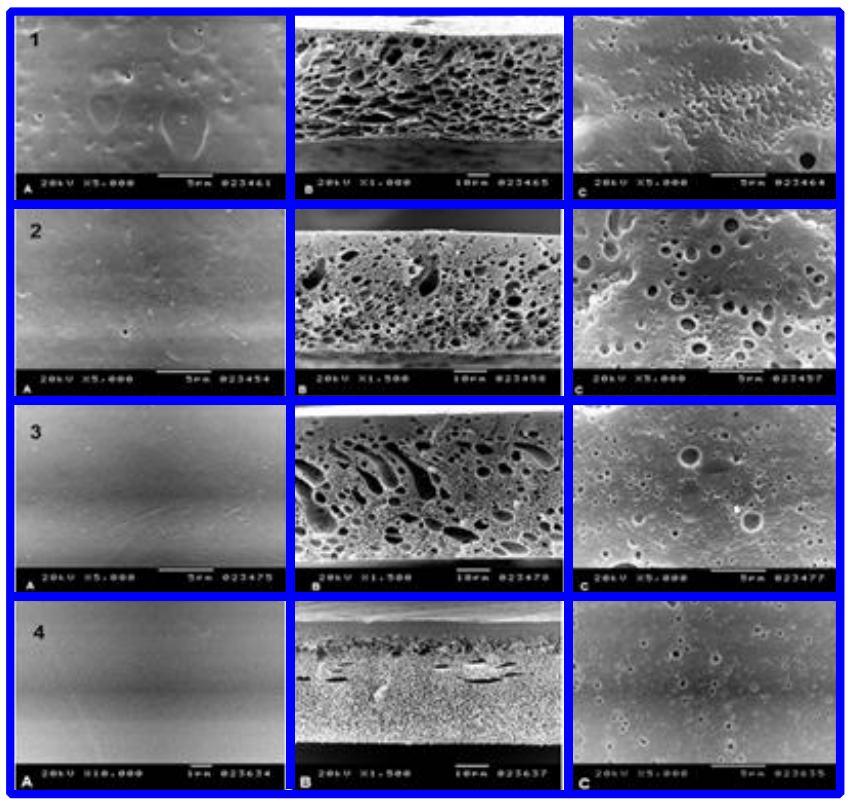




\section{Introduction}

Water sources, all over the world are being exposed to pollutant contamination. Industrial and agricultural activities affect the water quality $[1,2]$.

The coagulation-flocculation process reduces turbidity, total suspended solids (TSS) and natural organic matter [3, 4]. There are some problems with coagulationflocculation techniques regarding environmental impact of accumulated sludge as well as the cost of dosing chemicals [5-8].

Many coagulants such as aluminum sulfate, ferrous sulfate and ferric chloride are widely used in conventional wastewater treatment processes, resulting in the effective removal of wastewater particulates and impurities [9].

Abu Qir Fertilizers Company AFC is the leading Egyptian company in the field of Nitrogen fertilizers. Conventional coagulation-flocculation is used in AFC and many similar water treatment utilities with the aid of chemicals.

The sludge formed at the coagulationflocculation process is a significant problem as it is difficult to be discharged or recycled and due to its negative environmental impact.

Membrane processes are widely used in water desalination, wastewater treatment, removal of heavy metal ions, pesticides and many other micro pollutants. They are also used in the fabrication of chemicals and food products, and they are playing an important part in environmental protection [10-12].

Depending on the membrane nature and characteristics, a process and operating conditions are to be chosen. Among the processes, ultrafiltration has a large potential for applications in various fields: biotechnology, pharmacy and water treatment [13-15].

The new development of applications relies on the availability of membranes having high permeability and high fouling and chemical resistances. Fouling resistance and high permeability would be obtained by improvements in the membrane hydrophilicity, while chemical resistance would come from the intrinsic properties of the polymer materials [16].

Polysulfone PSF seems to be the most important material that is used for membranes fabrication. This is due to its reasonable price, good film forming ability and thermal, mechanical and chemical resistances, but PSF has some drawbacks as it is a hydrophobic membrane and subjected to membrane fouling, so many research papers were dedicated to improve its hydrophilicity $[17,18]$.

M'Bareck et al. $[19,20]$ introduced a simple 
method that makes it possible to fabricate ultrafiltration membranes that reject salt/organic pollutant molecules while keeping the PSF advantage by blending PSF with PAA polymer for heavy metal removal. This work aimed at fabrication and characterization of ultrafiltration membranes based on polysulfone and Polyacrylic acid as an alternative technique for conventional coagulation-flocculation.

\section{Experimental}

\subsection{Materials}

N, N Dimethylformamide (Aldrich), Polysulfone resin pellets approx. Mwt 60,000 Da (Acros Organics), Polyacrylic acid Mwt 500,000 Da (Fluka Chemika) and EDTA $0.01 \mathrm{M}$ analar grade (Sigma Aldrich). All chemicals were used as received without further treatment.

\subsection{Instruments}

IR spectra were recorded in the wavenumber range of $4000-400 \mathrm{~cm}^{-1}$ using
FTIR spectrometer (PerkinElmer-Spectrum BX 11), the cross sectional, surface, and bottom images of the membranes were obtained using SEM (XL 30 JEOL). The contact angles were measured using (Rame Hart instrument) and with the aid of micro syringe (Hamilton Company, Reno, NV). Tensile strength measurements were done using (Lloyd - LR 10K) tensile tester. Membrane thicknesses were measured using (Mitutoyo Vogel digiplus) digital micrometer. For membrane performance a locally manufactured Cross-Flow ultrafiltration cell system is used (Figure 1). The cell was manufactured from Stainless steel 316 alloy and it has a membrane active area $=50.7 \mathrm{~cm}^{2}$. Turbidity measurements were used (Cyberscan WL Turbidimeter). Absorbance measurements were performed using (Shimadzu UV-1800 UV-visible spectrophotometer) at $254 \mathrm{~nm}$ with a $1.0 \mathrm{~cm}$ path length quartz cell. DOC measurements were performed using (Shimadzu TOC-V CSN) instrument.
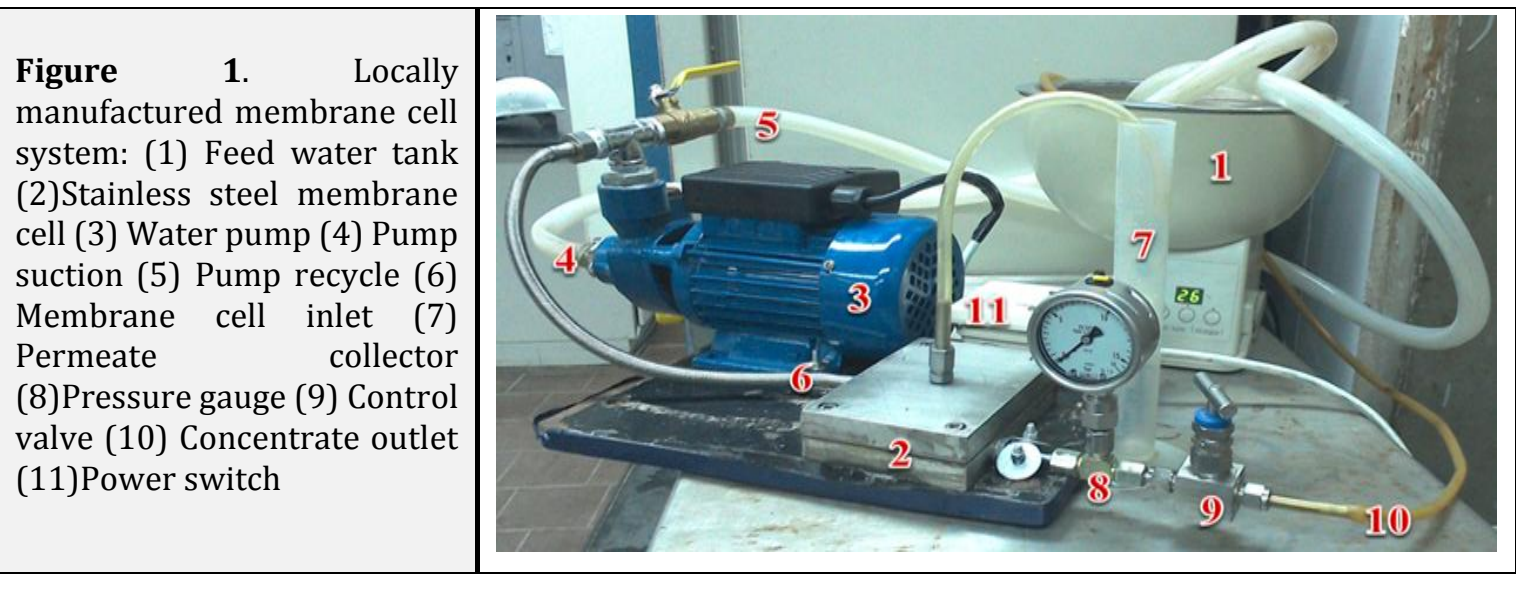


\section{Results and discussion}

\subsection{Membrane preparation.}

The UF membranes were prepared by adding different weights of PAA powder into a solution of $17.0 \mathrm{wt} \%$ PSF in DMF. At room temperature, the de-bubbled polymer solutions were casted onto a glass plate with a gap set to $250 \mu \mathrm{m}$ using Adjustable Elcometer casting knife and Zehntner ZAA 2300 automatic film applicator. The cast liquid-films were immersed immediately in a demineralized water coagulation bath $(\mathrm{pH}=7.2$, conductivity $=0.5 \mu \mathrm{S} / \mathrm{cm})$. A white solid film was stripped off the glass plate a little moment after immersion. The coagulated membranes were washed several times with demineralized water and stored in demineralized water. (Table 1) shows the different compositions of the prepared UF, which explains some membranes behaviors.

\subsection{Membrane characterization.}

\subsubsection{Chemical Structure of membranes: (FTIR)}

The peak at $1720 \mathrm{~cm}^{-1}$ in the UF membranes spectra which can be assigned to the stretching vibration of the carboxylic $\mathrm{C}=\mathrm{O}$ group of $\mathrm{PAA}$, indicates the presence of PAA in the membrane blend. Using the peak of $\mathrm{C}=\mathrm{C}$ double bond at $1585 \mathrm{~cm}^{-1}$ in PSF backbone as a reference, the ratio of the absorbance at $1720 \mathrm{~cm}^{-1}$ to $1585 \mathrm{~cm}^{-1}$ $\left(A_{1720} / A_{1585}\right)$ was used to quantify the PAA immobilization in the PSF matrix (Figure 2). There is an increase in $\left(A_{1720} / A_{1585}\right)$ which means that the PAA polymer, in spite of its water solubility, is well immobilized in the PSF matrix [20].

Table 1. Different compositions of PSF/PAAUF membranes

\begin{tabular}{|c|c|c|c|c|}
\hline $\begin{array}{l}\text { Membrane } \\
\text { Code }\end{array}$ & PAA/PSF & $\frac{P S F}{\text { Total solution }} \%$ & $\frac{P A A}{\text { Total solution }} \%$ & $\begin{array}{c}\text { Membrane } \\
\text { Thickness }(\mu \mathrm{m})\end{array}$ \\
\hline AS5 & $5 / 95$ & 16.9 & 0.9 & 118 \\
\hline AS10 & $10 / 90$ & 16.7 & 1.9 & 140 \\
\hline AS 15 & $15 / 85$ & 16.5 & 2.9 & 132 \\
\hline AS 20 & $20 / 80$ & 16.3 & 4.1 & 146 \\
\hline
\end{tabular}

Figure 2. $(\mathrm{C}=\mathrm{O}$ stretching at $1720 \mathrm{~cm}^{-1}$ to $\mathrm{C}=\mathrm{C}$ stretching at $1585 \mathrm{~cm}^{-1}$ ) against PAA\%

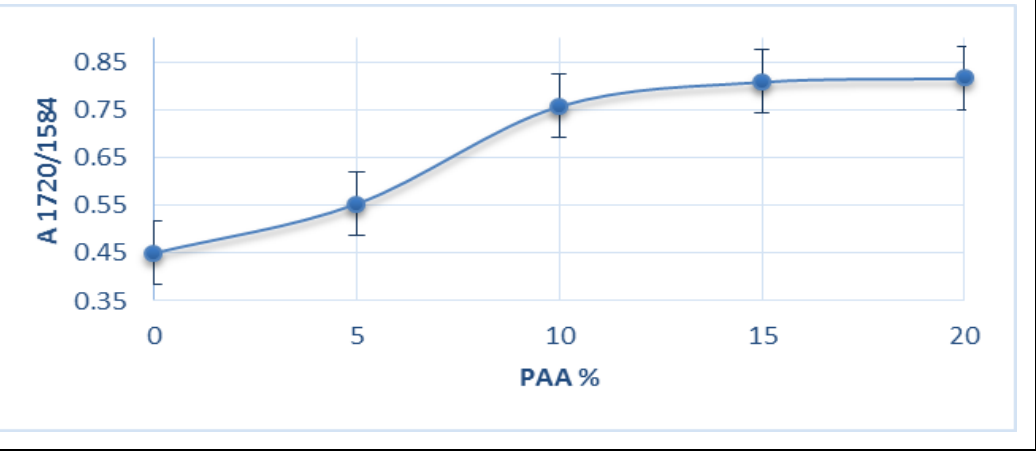




\subsubsection{Morphology of membranes: SEM}

The morphological images of the functionalized membranes cross section were snapped under liquid nitrogen to give a generally consistent and clean break. The membranes were sputter coated with thin film of gold. The membranes were mounted on a brass plate using doublesided adhesion tape in a lateral position.

The UF membranes show asymmetric structure consisting of a dense top layer and a porous sub layer. The membranes appear to have channels extending from the top to the bottom and sometimes have sponge like structure. The lower parts of the membranes have larger cavities.
The sub layer seems to have finger-like macrovoid cavities as well as honeycomb like pores opened into the macrovoids.

As seen in (Figure 3) the most noticeable difference between the membranes of various PAA contents is the gradient in pore size of the pores. The larger pore size which were found in AS 5 may be attributed to its lower total polymer content and to the delay of phase separation due to the addition of hydrophilic polymer PAA to the casting dope $[21,22]$.

As the total polymer concentration in the dope increases, more compact membrane structure was obtained in coagulation, because of a higher density of polymer chains that are coagulated by the water bath [23].
Figure 3. SEM (A) top surface,(B) cross section and (C) bottom for (1): AS 5 , (2)AS 10 ,(3) AS 15 and (4) AS 20 membranes.

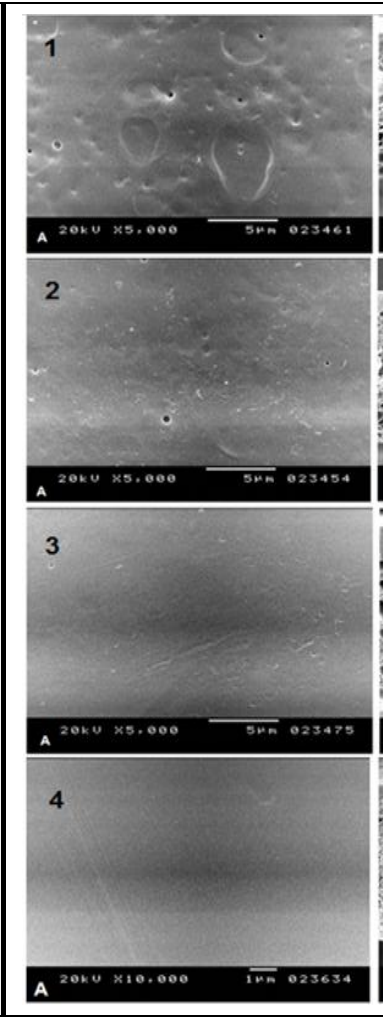

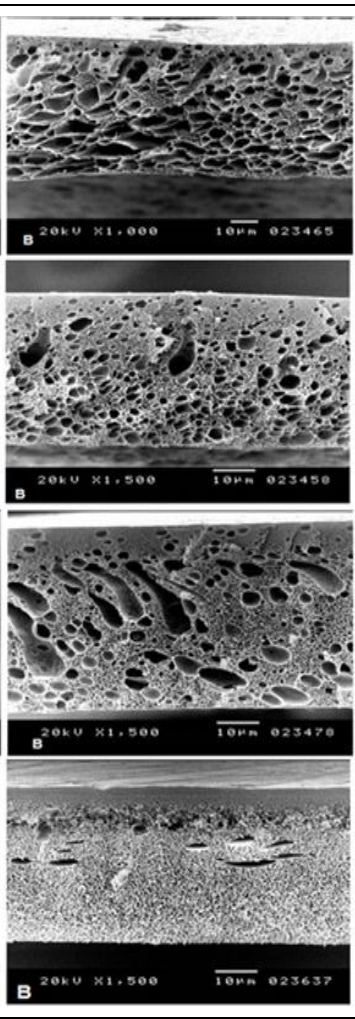

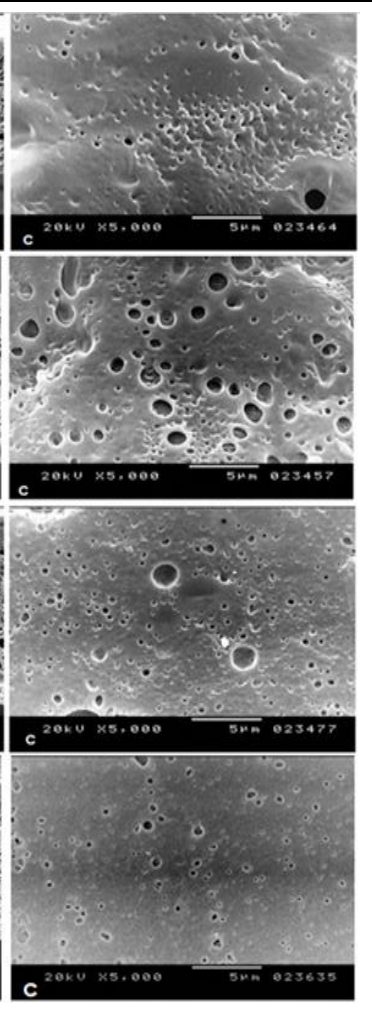




\subsubsection{Membrane Porosity}

Membrane porosity was measured by the method of "dry-wet weight" to examine the water content in the prepared membranes. Wet membranes were weighed after mopping superficial water with a filter paper $(\mathrm{Ww})$. Then they were placed in an oven at $60^{\circ} \mathrm{C}$ for 24 hours, further drying was done in a vacuum oven at $80^{\circ} \mathrm{C}$ for 24 hours to obtain the weight of the dry membrane (Wdr). The porosity P (\%) was evaluated using equation (1):

$$
P(\%)=\frac{W w-W d r}{W w} \times 100
$$

As described by SEM as the total polymer concentration increases, more compact structure is obtained in coagulation and membrane porosity decreases [23]. SEM images show a decrease of pore size with the increase of the PAA content for the prepared membranes. As the PAA content increases, the total polymer content increases and porosity decreases (Figure 4). AS 5 membrane which has the lowest polymer content showed the highest porosity.

\subsubsection{Membrane hydrophilicity: Contact angle}

The membranes were prepared by cutting pieces at random locations within the membrane sheet. The samples were placed on a glass plate and were fixed with a tape. Then, five drops of distilled water $(2 \mu \mathrm{L})$ were placed on the sample surface. The contact angles were measured within $20 \mathrm{sec}$ after the water drops were placed.

Surface hydrophilicity is one of the most important factors in determining the antifouling property and performance of ultrafiltration membranes. The hydrophilicity of the membranes was evaluated by contact angle measurements. It is commonly accepted that the lower contact angle usually represents the greater tendency for water to wet the membrane, the higher surface energy and the higher hydrophilicity [24]. As seen in (Figure 4) the contact angle decreased with the increase of PAA content, which means that the membrane becomes more hydrophilic.

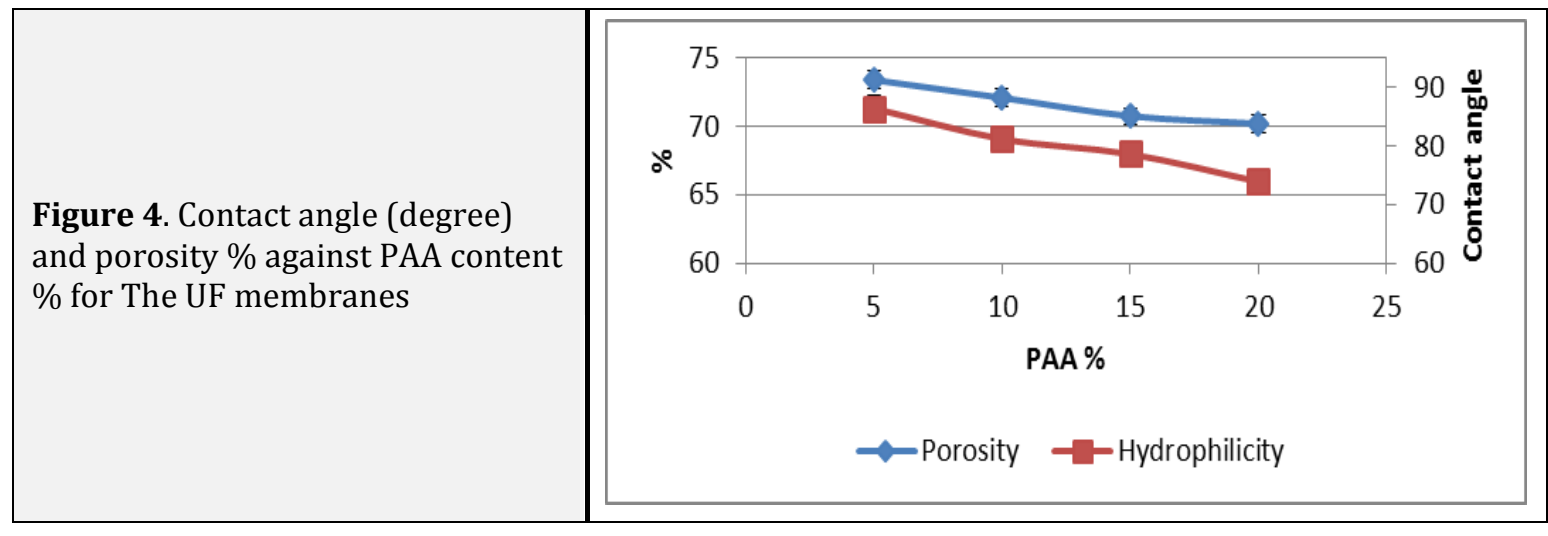




\subsubsection{Membrane mechanical stability:}

\section{Tensile strength}

The mechanical strength of a membrane is a key factor to evaluate its usefulness in practical application. It is generally accepted that PSF has high mechanical properties, also It is accepted that as the membrane becomes more hydrophilic it loses some of its mechanical properties [16]; we examined the mechanical strength of the membranes by testing their tensile strength and elongation. Tensile strength increases with the increase of PSF content and with the decrease of PAA content in polymer solution, as shown in (Figure 5); the highest PSF content and lowest PAA content membrane(AS 5) possesses the highest tensile strength of 7.2 MPa and elongation of $48.5 \%$.

\subsection{Performance measurements}

\subsubsection{Permeate flux}

The permeate flux $\mathrm{P}_{\mathrm{m}}\left(\mathrm{l} / \mathrm{m}^{2} . \mathrm{hr}\right)$ was calculated according to equation (2) where: $\mathrm{V}$ is the permeate volume (l), $\mathrm{S}$ is the membrane effective area $\left(\mathrm{m}^{2}\right)$, and the time interval (hr).

$\mathrm{P}_{\mathrm{m}}=\frac{1}{S} \frac{\mathrm{V}}{t}$

Permeate samples were collected at 15 minutes interval after discharging the first 7 $\mathrm{ml}$. The permeate flux of the membranes is qualitatively consistent with the membrane morphology and porosity [20].

As the total polymer in the casting solution decreases, the flux of the resulted membrane increases. The most porous membrane (AS5) shows the highest permeability which reaches $120.0 \mathrm{l} /\left(\mathrm{m}^{2} . \mathrm{h}\right)$. The decrease in the flux with the increase of PAA content can be related to the thickening of the dense skin and the decrease of pore size.

\subsubsection{Turbidity rejection}

The turbidity rejection $\left(\mathrm{R}_{\text {Turb. }}\right)$ was calculated according to equation (3):

$\mathrm{R}_{\text {Turb. }}=100 *\left(1-\frac{T p}{T f}\right)$

Where $T p$ is the turbidity of permeate and Tf is the turbidity of feed water.
Figure 5. Tensile stress MPa and elongation $\%$ against PAA content forAS membranes

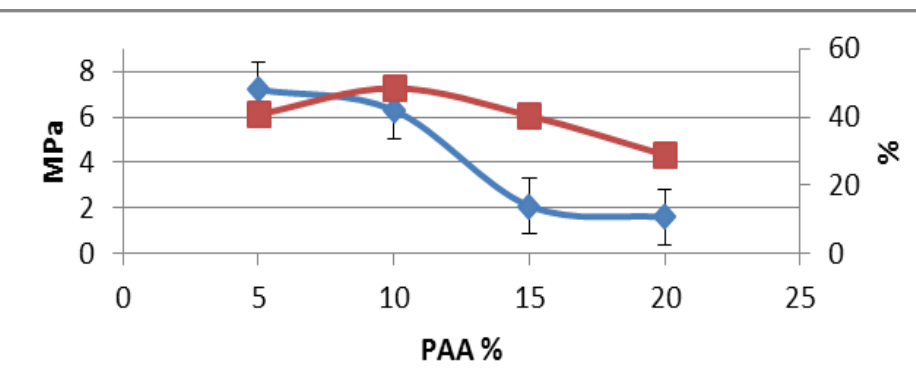

$\sim$ stress Mpa - extension \% 
All prepared membranes showed excellent turbidity rejection results ranging from $90 \%$ to $98 \%$ with slight increase of turbidity rejection with the increase of the total polymer content as membranes became less porous [25].

\subsubsection{Specific UV absorbance SUVA and DOC rejection}

A rapid method for estimating the aromatic C content of humic acids would be useful in studying the fate of nonpolar organic solutes in soils and natural waters [26]. Specific UV absorbance SUVA is defined as the UV absorbance of a water sample at a given wavelength normalized for dissolved organic carbon DOC concentration. SUVA determined at $254 \mathrm{~nm}$, which is assigned to the aromatic ring conjugation is strongly correlated with the percent aromaticity as an indication of the presence of humic substances which are the main component of DOC [26-28].

SUVA values were determined by dividing the UV absorbance measured at $\lambda=254 \mathrm{~nm}$ by the DOC concentration. SUVA for permeate $U V p$ and feed water $\mathrm{UV}_{\mathrm{f}}$ used to calculate DOC rejection ( $\mathrm{R}_{\mathrm{DOC}}$ ) according to equation (4):

$$
\mathrm{R}_{\mathrm{DOC}}=-100 *\left(1 \frac{U V p}{U V f}\right)
$$

The data shows that there is a slight increase in DOC rejection from $59 \%$ to $65 \%$ with the increase PAA content, as the membranes became less porous (Figure 6).

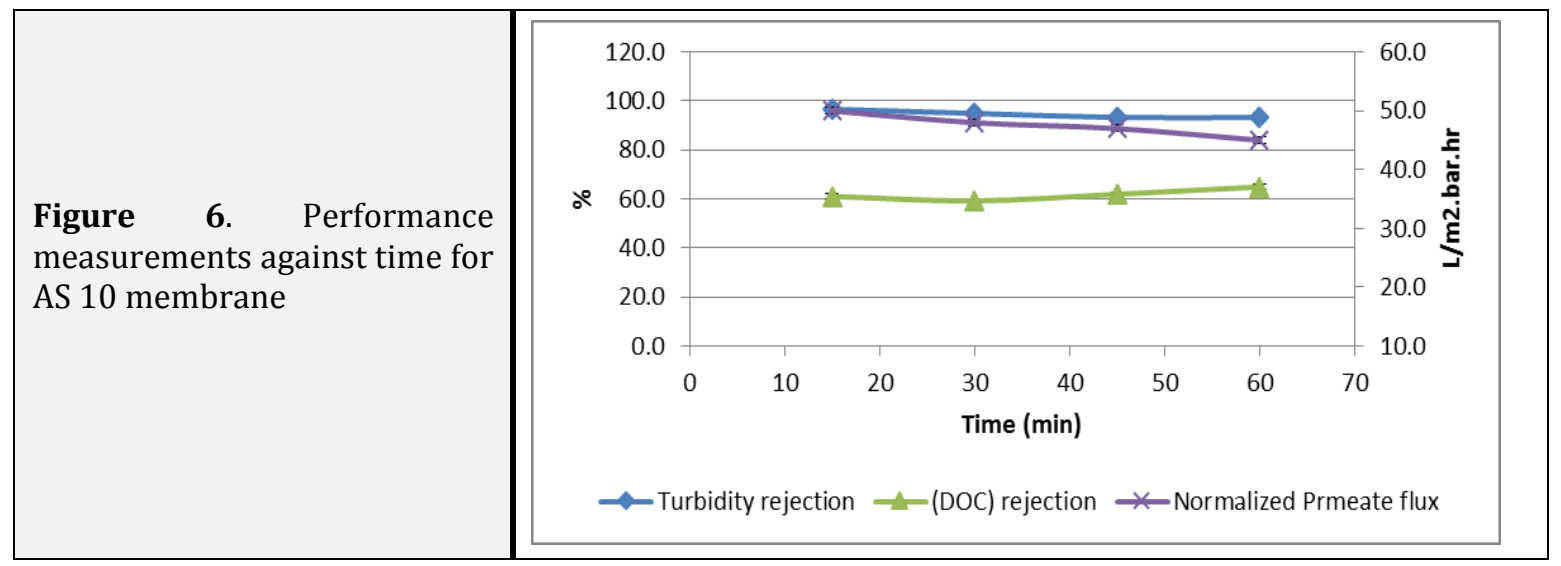

\section{Conclusion}

The addition of Polyacrylic acid PAA into polysulfone PSF resulted in more hydrophilic membranes. The PSF/PAA prepared membranes have good mechanical strength, show excellent turbidity rejection and DOC rejection. Furthermore, UF membranes, reduce chemicals dosing which, in turn, decrease sludge formation. This may introduce a good replacement for the conventional coagulation-flocculation 
process. Our future work will be dedicated to the improvement of flux and hardness ions retention.

\section{Acknowledgements}

Thanks to Mr. Reda Gaber, Eng. Hala Abdel Jalil and Main Workshop at AFC for manufacturing the membrane cell system. Many thanks to Chemist. Osama Waly, Mohamed Qenawy, Ahmed Atef and AFC Laboratories team for performing the mechanical strength testing and DOC analysis.

\section{References}

[1]. H.G. Gorchev, G. Ozolins, WHO Chron., 1984, 38, 104-108.

[2]. S. Ringoir, Verh. K. Acad. Geneeskd. Belg., 1992, 54, 179-185; discussion 185-188.

[3]. J. Leentvaar, M. Rebhun, Water Res., 1982, 16, 655-662

[4]. J. Bratby, Coagulation and Flocculation in Water and Wastewater Treatment, 2006.

[5]. R.A. Bergman, Desalinat., 1995, 102, 1124.

[6]. I. Al-Mutaz, I.A. Al-Anezi, "Silica removal during lime softening in water treatment plant," in International Conf. on Water Resources \& Arid Environment, 2004, p. 110.

[7]. L.R.J. van Vuuren, G.J. Stander, M.R. Henzen, P.G.J. Meiring, S.H.V. van Blerk, Water Res., 1967, 1, 463-474.
[8]. S.R. Roalson, J.H. Kweon, D.F. Lawler, G.E. Speitel, J. Am. Water Work. Associat., 2003, 95, 97-109.

[9]. D. Purkayastha, U. Mishra, S. Biswas, J. Water Process Eng., 2014, 2, 105-128.

[10]. E.N. Lightfoot, Chem. Eng. Sci., 1996, 51, 325-326.

[11]. L.F. Greenlee, D.F. Lawler, B.D. Freeman, B. Marrot, P. Moulin, Water Res., 2009, 43, 2317-2348.

[12]. I. Korus, K. Loska, Desalinat., 2009, 247, 390-395.

[13]. N.A. Ochoa, M. Masuelli, J. Marchese, J. Memb. Sci., 2006, 278, 457-463.

[14]. J.E. Yoo, J.H. Kim, Y. Kim, C.K. Kim, J. Memb. Sci., 2003, 216, 95-106.

[15]. B. Chakrabarty, A.K. Ghoshal, M.K. Purkait, J. Memb. Sci., 2008, 325, 427-437.

[16]. F. Zhang, W. Zhang, Y. Yu, B. Deng, J. Li,

J. Jin, J. Memb. Sci., 2013, 432, 25-32.

[17]. G. Kalaiselvi, P. Maheswari, S. Balasubramanian, D. Mohan, Desalinat., 2013, 325, 65-75.

[18]. M. Homayoonfal, A. Akbari, M.R. Mehrnia, Desalinat., 2010, 263, 217-225.

[19]. C.O. M'Bareck, Q.T. Nguyen, S. Alexandre, I. Zimmerlin, J. Memb. Sci., 2006, $278,10-18$.

[20]. C. Mbareck, Q.T. Nguyen, O.T. Alaoui, D. Barillier, J. Hazard. Mater., 2009, 171, 93101. 
[21]. H. Strathmann, K. Kock, P. Amar, R.W. Baker, Desalinat., 1975, 16, 179-203.

[22]. I.M. Wienk, R.M. Boom, M.A.M. Beerlage, A.M.W. Bulte, C.A. Smolders, H. Strathmann, J. Memb. Sci., 1996, 113, 361371.

[23]. A.F. Ismail, P.Y. Lai, Sep. Purific. Technol., 2003, 33, 127-143.

[24]. Y. Liu, X. Yue, S. Zhang, J. Ren, L. Yang, Q. Wang, G. Wang, Sep. Purific. Technol., 2012, 98, 298-307.
[25]. A. Alpatova, S. Verbych, M. Bryk, R. Nigmatullin, N. Hilal, Sep. Purific. Technol., 2004, 40, 155-162

[26]. S.J. Traina, J. Novak, N.E. Smeck, J. Environ. Quality, 1990, 19, 151.

[27]. J. Cho, G. Amy, J. Pellegrino, J. Memb. Sci., 2000, 164, 89-110.

[28]. J.L. Weishaar, G.R. Aiken, B.A. Bergamaschi, M.S. Fram, R. Fujii, K. Mopper, Environ. Sci. Technol., 2003, 37, 4702-4708.

How to cite this manuscript: M.S. Abdel Aal*, A.M. Ahmed, H.H. Abdelrahman, S.H. Kandil, Enhancing the Performance of Polysulfone Ultrafiltration Membranes by Mixing with Polyacrylic Acid for Canal Water Treatment, Adv. J. Chem. A, 2018, 1(2), 86-95. 